- General anaesthesia owes its development to the members of the young dental profession in the nineteenth century, who exploited its discovery for the benefit of their patients

- As an effective and efficient measure of pain control general anaesthesia remained a cornerstone of dental practice for over a century in the UK

- The decline of general anaesthesia was caused by better and safer alternatives of pain control and behavioural management becoming available

- Its final banning was caused by a failure, after repeated calls to create a funding environment in NHS dental practice that was able to put quality at its core

\title{
The provision of general anaesthesia in dental practice, an end which had to come?
}

\author{
D. P. Landes ${ }^{1}$
}

31 December 2001 was the final day on which a general anaesthetic could be given in a dental practice in UK. ${ }^{*}$ Henceforth all dental treatment requiring a general anaesthetic will have to take place in a hospital setting, which has immediate access to critical care facilities. ${ }^{1}$ This will mark the end of the association between dental practice and general anaesthesia which dates back to the very first recorded clinical procedure performed under general anaesthesia, when in 1844, Horace Wells an American dentist, had a tooth removed by his assistant using nitrous oxide in Hartford, Connecticut, USA. ${ }^{2}$

The reason for the removal of general anaesthesia from general dental practice and restricting its provision to a hospital environment is given on the grounds of safety and that its continued provision in general dental practice is unlikely to be made safe through more guidance and increased regulation. ${ }^{1}$ Is this conclusion actually correct and must we accept that general anaesthesia can never be safely provided outside hospitals?

The reasons for the final and subsequently terminal report into the use of general anaesthesia in dental practice in the UK are well known to many in the dental profession. The deaths of two children under GA in two dental practices, in the summer of 1998, led the then minister of Health, Alan Milburn, to set up an enquiry into the use of general anaesthesia in dental practice. These deaths were not simply tragic accidents; latter enquires showed that they may have been avoid-

${ }^{1 *}$ Consultant in Dental Public Health, Department of Public Health, County Durham and Darlington Health Authority, Lanchester Road, Durham DH1 5XZ

${ }^{*}$ Correspondence to: David P. Landes

Email:david.landes@public-health.durham-

ha.northy.nhs.uk

\section{Refereed Paper}

Received 11.04.01; Accepted 13.08.01

๑) British Dental Journal 2002; 192: 129-131
Between 1863 and 1881, it was reported that

Colton performed 121,709 nitrous oxide anaesthetics for dental treatment without a single fatality in the USA.

able. The deficiencies found in the clinical care provided were so serious that one of the anaesthetists involved was disciplined by the General Medical Council and another was found guilty of manslaughter. ${ }^{1}$

It was obvious that there were failures in the quality assurance in the practices involved for such verdicts to be reached; but why did dental practices providing general anaesthesia have such critical failures?

In the past the quality assurance in dental practices in the UK has been mainly through guidance from the General Dental Council and the Department of Health, supported by regulation through agencies such as the Health and Safety Executive and health authorities. What has only recently been considered as an appropriate vehicle to address issues of quality in general dental practice is the negotiation of fundamental changes in the way dentists are paid for the provision of services. Personal Dental Services pilots have for the first time since 1948 allowed local dentists and their health authorities to consider how best to reform the contract with practitioners, which would ensure high quality standards of care. ${ }^{3}$

\section{HISTORY OF GENERAL ANAESTHESIA}

General anaesthesia has always been associated with serious risks, however it has been widely used in dentistry for well over a century with relatively low mortality rates. Between 1863 and 1881 it was reported that Colton performed 121,709 nitrous oxide anaesthetics for dental treatment without a single fatality in the USA. ${ }^{4}$ The standards of training and equipment for resuscitation prevailing at the time were of course far poorer than those available today.

Two centuries ago, at a time when there were no effective local anaesthetics available it is hardly surprising that members of the dental profession in Britain quickly exploited general anaesthesia to provide

*In Wales slightly different arrangements apply. 
better care for their patients. In December 1846 Dr Francis Booth performed the extraction of a tooth using ether in London after he received news from the USA of the anaesthetic technique. Only one month later in January 1847, a letter appeared in the Manchester Guardian from a dentist describing the painless extraction of a tooth using general anaesthesia. ${ }^{5}$

Local anaesthesia for dental practice was only experimental in the early part of the previous century, and just started to become available in an easily useable form during the interwar years 1918-1939. It was only after the Second World War that the dental profession had an effective and easy-to-use local anaesthetic available to it, with the introduction of lidocaine in $1946 .{ }^{6}$

The post war history of general anaesthesia in dental practice in the United Kingdom is one of continued demand for the service partly based upon need, but also on cultural norms. ${ }^{7}$ This was associated with continuing concern about the standards of the provision of general anaesthesia in dentistry. These concerns resulted in a succession of reports stretching back over a quarter of a century into the use of general anaesthesia in dental practice, shown in Table 1.

\section{RECOMMENDATIONS}

While many of the recommendations in the reports in Table 1 were implemented, a key issue of changing the way dentists are paid to provide general anaesthesia in the NHS identified in latter reports was never addressed. ${ }^{8}$ The issue of the payment system for dentists not delivering the correct environment for the provision of general anaesthesia in dental practice was again highlighted by two Health Authority enquiries into the deaths of children in Barnsley and Derbyshire. ${ }^{9,10}$ Professional guidance from the General Dental Council is that general anaesthesia should be avoided wherever possible and promotes the use of alternative behavioural management techiques. ${ }^{11}$ However, there has been continual debate that the method used to remunerate dentists has acted as a disincentive to the use of sedation and the provision of treatment for children. Treatment under inhalation sedation is a safe and effective alternative behavioural management technique to general anaesthesia for children, but may take over four times longer than providing treatment under general anaesthesia. ${ }^{12}$ Regrettably, the extra time to treat a patient under sedation compared with general anaesthesia has not been recognised in the way the GDS is funded, while the capitation system used to pay for children's dentistry in the past has been blamed in part for reducing the amount of restorative care

Table 1 Major Reports on General Anaesthesia in Dental Practice 1967-2000

\begin{tabular}{ll}
\hline Report & Year of publication \\
\hline $\begin{array}{l}\text { Dental Anaesthesia, Central Health } \\
\text { Services Council, Standing Medical }\end{array}$ & 1967 \\
and Dental Advisory Committee. & \\
\hline $\begin{array}{l}\text { Spence, Report of joint working party } \\
\text { on Anaesthesia in General Dental }\end{array}$ & 1981 \\
Practice. & 1981 \\
\hline $\begin{array}{l}\text { Wylie, Report of the Working Party } \\
\text { of training in Dental Anaesthesia. }\end{array}$ \\
\hline $\begin{array}{l}\text { Seward, Report of the Inter-Faculty } \\
\text { Working Party on the implementation } \\
\text { of the Wylie Report. }\end{array}$ \\
\hline $\begin{array}{l}\text { Poswillo, General Anaesthesia } \\
\text { Sedation and Resuscitation in }\end{array}$ \\
$\begin{array}{l}\text { Dentistry, Report of an expert } \\
\text { working Party. }\end{array}$ \\
\hline $\begin{array}{l}\text { Dental General Anaesthesia, Clinical } \\
\text { Standards Advisory Group }\end{array}$ \\
$\begin{array}{l}\text { Standards and guidelines for General } \\
\text { Anaesthesia in Dentistry, The Royal } \\
\text { College of Anaesthetists. }\end{array}$ \\
$\begin{array}{l}\text { A Conscious Decision, General } \\
\text { Anaesthesia and sedation in primary } \\
\text { dental care, Department of Health. }\end{array}$ \\
\hline
\end{tabular}

provided by dentists. ${ }^{13}$ The low fees paid to dentists under the capitation system for paediatric dentistry has been suggested as making it impossible for GDPs to treat children with decay to the necessary standard. ${ }^{14}$ Furthermore practitioners have expressed the view that the substantial investment in equipment required to undertake general anaesthesia in dental practice means they had to have a considerable level of activity in order to recoup their initial investment. ${ }^{15}$

\section{It is regrettable that the} Government has indicated that no fourth wave Personal Dental Service pilots involving sedation are to be approved

This evidence points to the fact that there has been a failure to promote the correct funding environment in the UK which would firstly encourage better treatment for children in the NHS (including the use of relative anaesthesia) and a failure to produce an environment where practitioners providing general anaesthesia are rewarded for quality of care rather than quantity of activity. When services are not reliant on activity for income there is far more scope to address issues of quality, undertake audit and promote alternatives to general anaesthesia for patients. ${ }^{16}$

\section{PERSONAL DENTAL SERVICES}

Personal Dental Services have provided the opportunity for the dental profession to fundamentally rethink how services can be funded. The individual contracts with GDPs can underpin improvements in the quality of services for patients and furthermore remove those perverse incentives which have for decades prevented those changes which would have undoubtedly helped to prevent tragedies in the use of general anaesthesia in dental practice. The answer to the problems of general anaesthesia in dental practice were never going to be addressed by regulation and guidance alone, but may have been resolved by changing the environment in which GDS dental practice is funded in the UK to one which promoted and rewarded quality.

It is regrettable that the Government has indicated that no fourth wave Personal Dental Service pilots involving sedation are to be approved. ${ }^{17}$ PDS contracts can be used to improve the quality of care and remove the financial barriers to the wider use of sedation in general practice. There has already has been one death associated with sedation in the UK. ${ }^{18}$ This comes at a time when the Government will in the future be requiring dentists to examine their clinical practice to "ensure that a high quality of service is being maintained or further improved. ${ }^{19}$ How can practitioners be expected to improve the quality of the serv- 
ice they provide if the funding environment provided by the Government does not support improvements in quality?

\section{CONCLUSION}

The GDS system of payment for treatment under general anaesthesia is driven to a degree by numbers of patients seen, courses of treatment provided and levels of income required to be economically viable. There are two lessons from the loss of general anaesthesia. Society will not accept tragedies involving children in dental practice however rare, and the profession must press the Government to reform the funding mechanism for dental practice to produce an environment which will underpin the delivery of high quality care.

The removal of general anaesthesia from dental practice was probably inevitable in the light of the development of new standards for the provision of critical care facilities in the NHS, ${ }^{20}$ what will be lost from dental practice next, if the practising environment is not changed?

1. A conscious decision, a review of the use of general anaesthesia and conscious sedation in primary dental care. London: Department of Health, 2000.

2. Laird W R E, The Yankee dodge: some new observations on the discovery of anaesthesia. BrDent J 1990; 169: 217-219.

3. Guidance on making a proposal to pilot personal dental services. London: Department of Health, 1998.

4. Dookun R, Lyne J P, Robb N D. Nitrous Oxide past, present and future. SAAD Digest 1997; 14:13-35.

5. Healy TE J, Un E N. The Manchurian Way. Anaesthesia 1992; 47: 882-886.

6. Howe L G, Whitehead FI M. The development of loca anaesthesia in dentistry. In Howe L G, and Whitehead FI M. Local Anaesthesia in Dentistry. 2nd ed. pp.1115. Bristol: John Wright and Sons, 1946.

7. General anaesthesia, sedation and resuscitation in dentistry: report of an expert working party. London : Department of Health, 1990.

8. Clinical Standards Advisory Group. Dental General Anaesthesia pp.33 London: HMSO, 1995.

9. Southern Derbyshire Health Authority. Report of the internal enquiry into the death of Katie Dougal. Derby: Southern Derbyshire Health Authority, 1996.

10. Barnsley Heath Authority. Report of the enquiry into the circumstances surrounding the death of Bradley Miller. Barnsley: Barnsley Health Authority, 1999.
11. General Dental Council. Maintaining standards quidance to dentists on professional and personal conduct. London: General Dental Council, 1998.

12. Blain K M, Hill FJ. The use of inhalation sedation and local anaesthesia as an alternative to general anaesthesia for dental extraction in children. Br Dent J 1998; 184: 608-611.

13. Whittle KW, Whittle J G, Dental caries in 12 year-old children and the effectiveness of dental services in Salford, UK in 1960, 1988 and 1997. Br Dent J 1998; 184: 394-396.

14. Curzon M E J, Pollard M A. Do we still care about children's teeth? BrDent J 1997: 182: 242-244.

15. Hastings $G B$, Lawther $S$, Eadie D R, Haywood A, Lowry $R$, Evans D. General Anaesthesia: who decides and why? BrDent J 1994; 177: 332-336

16. Landes D P, Clayton-Smith A J. The role of pregeneral anaesthetic assessment for patients referred by general dental practitioners to the Community Dental Service. Community Dental Health 1996; 13:169-171.

17. Modernising NHS dentistry - implementing the NHS plan-Guidance to Health Authorities. London: Department of Health, 2001.

18. Fleming N, Report case Richard Kaul. The Express 23 Feb, 2001; 25.

19. Modernising NHS dentistry-clinical audit and peer review in the GDS. London: Department of Health, 2001

20. Comprehensive critical care a review of adult critical care services. London: Department of Health, 2000. 